\title{
Inequalities in Respite Service Provision: Insights from a National, Longitudinal Study of People with Intellectual Disabilities
}

\author{
Roy McConkey*, Fionnola Kelly ${ }^{\dagger}$, Hasheem Mannan ${ }^{\dagger}$ and Sarah Craig ${ }^{\dagger}$ \\ ${ }^{*}$ Institute of Nursing Research, University of Ulster, Ulster, UK; ${ }^{\dagger}$ Health Research Board, Dublin, Ireland; ${ }^{\dagger}$ National Institute of \\ Intellectual Disability, Trinity College, Dublin, Ireland
}

\section{Accepted for publication 19 September 2009}

Background Respite or short breaks are frequently sought by parents and demand for them usually exceeds their availability.

Methods Using data from a national database in Ireland of around 16000 persons living with family carers, the availability of overnight respite provision was monitored over an 8-year period along with the recorded needs for such services.

Results Despite marked rises in the number of people receiving respite breaks resulting from increased government funding, there were marked inequalities in the availability of provision across the country. In recent years the inequalities decreased but still remained. The proportion of families requiring breaks also rose and a similar pattern of inequalities were found here too. Only a small proportion of families who had a recorded need in 1999 were receiving respite services 8 years later and over one third had a continuing need recorded.

Conclusion This study highlighted some of the complexities in reducing inequalities in the provision of respite services and in identifying the need for them. It would be advantageous to develop more explicit criteria regarding the need for respite provision and to record the family's preferences for the form this provision might take. These adjustments would add to the value of any national database as a service planning tool.

Keywords: family carers, inequality, intellectual disability, Ireland, respite, short breaks

\section{Introduction}

Internationally, the majority of persons with intellectual disabilities live with family carers (Braddock et al. 2001). This is especially so during childhood but these arrangements continue well into the person's adult years. Hence, support for carers must be a major emphasis in modern service provision, especially giving the demographic changes of family structures that are occurring in Western societies (Hantrais 2004), for example, the increase in lone parent caring (Kelly et al. 2009). However, increased demand for support services, such as respite breaks for carers, cannot always be met and hence issues arise around the equitable distribution of scarce resources.

One way of both monitoring demand and assessing equity in service provision is through the use of national datasets. The Republic of Ireland (population 4.2 million in 2006) is one of the few countries internationally to have established a national database of persons with an intellectual disability that is updated annually (Kelly et al. 2009). This has been instrumental in planning for, and the distribution of, increased Governmental funding for extra service provision to meet the growing numbers of Irish persons requiring services. For example, in the period between 1999 and 2003 the non-capital health and social service expenditure on intellectual disability services nearly doubled from $€ 363$ million to $€ 693$ million (Department of Health and Children 2005). The increase in service provision that arose from this investment should be ascertainable using a national service database and, more pertinently, to identify the extent to which these resources were equitably distributed across the state.

In addition, a regularly updated, national database also enables longitudinal research to be undertaken with 
total populations, hence overcoming two persistent problems that beset much research in the field of intellectual disability which is usually dependent on selected samples at a single point in time. In this study, comparisons were drawn over an 8-year period of the characteristics of people who both used, and who were recorded as needing, respite services in the form of short breaks away from the family home. This is the most favoured form of break for carers of children with complex needs (MacDonald \& Callery 2004) and those who face particular burdens and demands as care-givers (Haveman et al. 1997).

A great deal of research in Ireland and elsewhere has demonstrated the value that carers place on having short breaks from their caring responsibilities (Beresford 1995). Traditionally these have taken the form of the person being looked after in a special facility by paid professional staff although in recent years other forms of provision have emerged (McConkey \& Adams 2000). There is research evidence of the unequal availability of these and other family support services across countries or regions such as the United States (Rizzolo et al. 2004; Kang \& Harrington 2008) or in parts of the United Kingdom (Smiley et al. 2002; McConkey 2005). To date there is little analysis of the reasons for these inequalities and how they change over time.

Within Ireland, the bulk of respite provision for children and adults takes the form of short-term admissions to some form of residential establishment. In many instances these have grown out of the boarding schools previously provided by religious orders for pupils with 'mental handicap' or they form part of the residential care services that they and other voluntary organizations are funded to provide by the State. In recent years dedicated respite care units have been provided within ordinary houses in community settings, mostly by voluntary organizations.

The existence of a national dataset meant that comparisons could be drawn across different regions in the provision of respite services. As in other countries, the development of intellectual disability services in Ireland has been uneven with developments occurring first in major cities. However, this variation was compounded in Ireland as many services began as local, charitable initiatives with little direction or funding from central government (Department of Health 1990). In recent years, this has changed with new funding arrangements and national policies to guide service provision, although the last formal review of services was published in 1990. This review proposed a shift away from institutional provision and the need to provide greater support to family carers. However, no national action plan was proposed for achieving this. Indeed, the legacy remains of autonomous providers serving discrete geographical areas. A national dataset that allows comparisons in provision across areas is one vehicle for driving greater equity in access to services across the State.

Although the data presented in this study may be specific to Ireland it is likely that some of the findings would have wider applicability in countries with similar socio-economic demographics and a diversity of service systems such as those in continental Europe, North America, Australia and New Zealand. Also the content of the database and the examples given of its usage would assist with the creation of similar datasets elsewhere.

In summary then, the main aims of the study were:

- To monitor changes in the usage of out-of-home, overnight respite services over an 8-year period of increased resourcing of intellectual disability services within the Republic of Ireland.

- To identify the characteristics of families using overnight respite services and those who are recorded as needing them.

- To assess equity of provision across the country.

\section{Method}

Until a recent re-organization, Ireland was divided into eight health boards (later known as health service areas) with responsibility for service provision, either directly or more typically through funding of non-governmental agencies. In each area, a co-ordinator is responsible for identifying the service personnel who either complete or update a database pro forma for each child or adult with an intellectual disability known to him/her. This dataset forms part of a regional database. Data on individuals are updated annually. Information from the regional databases, excluding personal details, is available to the Disability Databases Unit of the Health Research Board which manages the database on behalf of the Department of Health and Children and which undertakes analysis of the data at a national level. An annual report is produced that provides details of the characteristics of persons with an intellectual disability within the State, the services they receive and those they require in the future (See Kelly et al. 2009 for the latest example).

These data represent all individuals throughout the State who are known to have a mild, moderate, severe or profound intellectual disability (using ICD-10 criteria) or anyone else in receipt of, or in need of, a specialist intellectual disability service. In all, 25613 persons were 
recorded in 2007 representing a prevalence rate of 6.04 per 1000 population.

Consent is sought before an individual is registered on the database and audits of the database have estimated that nearly total coverage has been achieved of school-age children and older persons with moderate, severe and profound disabilities. However, those with milder forms of intellectual disabilities are only registered if they are in receipt of, or they require specialized services. Nonetheless, the prevalence of people registered is higher than regional databases in England (Emerson and Hatton 2004) and slightly lower than reported for the United States (Larson et al. 2001).

Around two-thirds of registered persons live with family carers, that is, parents, siblings, other relatives or foster/adoptive families (Barron et al. 2006). In order to detect trends in respite care arrangements over an 8 -year period, the datasets for three different years were selected: 1999, 2003 and 2007. In each dataset, all persons recorded as living at home with parental or other carers were selected (around 16000 persons per year).

Respite care is recorded as a break outside of the family home, most usually in a special facility or with a host family, but in the 3 years studied, only around 5\% of breaks were with host families. Specialist facilities include dedicated respite units provided in ordinary community housing, overnight stays in campus style residential settings or in community group homes at weekends when the residents of the homes return to their families. In this study, all these forms of accommodation are grouped together as a respite service. The number of nights of respite that a person received was not recorded on the database although this started to happen from 2007 onwards. An analysis of these data is contained in another paper (Kelly et al. submitted for publication).

Each year the service staff most involved with the persons review their needs for services in conjunction with families as appropriate and the details are updated on the database. For those persons living with family carers or in other family settings (such as foster care arrangements), the need for respite breaks can be recorded on the database. This need can take one of two forms: enhanced provision to the respite breaks already provided or as a new requirement for respite breaks.

The datasets for 3 years were chosen. Although the national database had been started in 1996, it was not fully functional until 1999, the first year chosen for this study. This year also marked the commencement of a major investment by the Government in intellectual disability services driven in part by the evidence of unmet need that the database had started to identify. This was predomi- nantly for full-time residential care and day service provision although respite breaks for carers also featured.

The datasets for two further years were also chosen, each 4 years apart: 2003 and 2007. As each person has a unique identifier, it is possible to trace their records over the 8-year period. In addition, analyses can be made of all the persons recorded on the database for each chosen year. The latter would include people joining the database.

Two further points need to be noted with respect to these comparisons. The health service areas had changed during this period but people were allocated to the Board area in which they had been resident in 1999 in order to maintain comparability. Also in 2003 and 2007 the need for two residential services could be recorded for each person whereas in 1999 only one such service could be recorded. This could mean a small undercounting in that year of people needing respite services. Based on the proportion of persons for whom a second need had been recorded in 2003 and 2007, this undercount was estimated at around $22 \%$.

In the three selected years, all the records were chosen for people living with family carers or in family settings, such as with foster or adoptive parents.

\section{Findings}

The findings are presented in four sections.

- Section 1 presents the overall proportions of the population of persons with intellectual disability living with family carers who received or needed respite breaks. This compares changes over time for the total population of people living with family carers in the Republic of Ireland.

- Section 2 supplements these data by following through the 1999 cohort of persons living with family carers over 8 years to determine changes in their use of respite breaks and whether particular needs were met.

- Section 3 presents the findings from regression analyses to identify the predictors of respite usage.

- Section 4 reports the findings of similar analyses based on recorded need for respite.

\section{Section I: Comparative changes in respite usage and need}

Table 1 presents the proportion of children and adults in receipt of respite breaks and shows the notable increase over the 8 years but particularly in the period 1999-2003. Overall, proportionately more adult persons than children received respite breaks in all 3 years. 


\begin{tabular}{llll}
\hline $\begin{array}{l}\text { Age of person } \\
\text { with ID (years) }\end{array}$ & 1999 & 2003 & 2007 \\
\hline $0-19$ & $11.8 \% n=8737$ & $18.3 \% n=8007$ & $21.0 \% n=8581$ \\
20 plus & $16.6 \% n=8255$ & $30.0 \% n=7555$ & $37.0 \% n=7778$ \\
All ages & $14.1 \% n=16992$ & $24.0 \% n=15562$ & $28.6 \% n=16359$ \\
\hline
\end{tabular}

Table I Percentage of people living with family carers who received respite breaks in each year (The total numbers within each cell are also noted)

Source: National Intellectual Disability Database, Health Research Board, Dublin.

Table 2 similarly documents the recorded need for respite breaks, either as an enhancement to current provision or as a new service that is not received. (NB In order to correct for a possible undercount of need in 1999, the percentages for 1999 have been increased by a factor of $22 \%$ as noted earlier). Both types of increased needs show a marked increase over the 8 years, although the requirements for 'new' provision for children tended to exceed the need for enhanced services. Nonetheless the need for enhanced services had increased as a proportion of those receiving respite breaks: namely in 1999, 9\% of persons already receiving respite services were recorded as needing an enhanced service whereas this proportion had risen to $27 \%$ (in 2003) and to $26 \%$ (in 2007) of those receiving respite services in those years.

\section{Section 2: Longitudinal analyses of 1999 cohort}

Another way of looking at change over time is to follow a cohort of persons, in this instance those persons living with family carers in 1999, to see their use of respite provision in subsequent years, and whether their needs for such services were met.

In 1999 a total of 2396 persons had received respite breaks. But as Table 3 shows, the numbers dropped in 2003 with a further drop in 2007. Over the 8-year period a proportion of respite users moved from family care into full-time residential accommodation, proportionately more of whom had been living with single carers (i.e. $35 \%$ of those who moved compared with $19 \%$ living with single carers in the sample overall see McConkey et al. submitted for publication, for more details). A further proportion discontinued respite for a variety of other reasons, notably death, move out of Ireland or no longer in need of intellectual disability services. However, of particular interest, those are who continue to live with family carers but who no longer avail of respite. These included both children and adult persons (33 and 67\%, respectively, of the total).

Over this 8-year period a further 1899 persons in the 1999 cohort who had previously not accessed respite services were recorded as availing of them in 2003 and this had risen to an additional 2537 persons by

\begin{tabular}{|c|c|c|c|c|}
\hline $\begin{array}{l}\text { Age of person } \\
\text { with ID (years) }\end{array}$ & Need & $1999^{*}$ & 2003 & 2007 \\
\hline \multirow[t]{4}{*}{ 0-19 } & Enhanced & $2.1 \%$ & $7.6 \%$ & $8.4 \%$ \\
\hline & New & $5.6 \%$ & $8.9 \%$ & $9.9 \%$ \\
\hline & Total Need & $7.7 \%$ & $16.5 \%$ & $18.3 \%$ \\
\hline & $n$ & 8737 & 8007 & 8581 \\
\hline \multirow[t]{4}{*}{20 plus } & Enhanced & $0.8 \%$ & $9.2 \%$ & $12.8 \%$ \\
\hline & New & $5.3 \%$ & $8.1 \%$ & $11.3 \%$ \\
\hline & Total Need & $6.1 \%$ & $17.3 \%$ & $24.1 \%$ \\
\hline & $n$ & 8255 & 7555 & 7778 \\
\hline \multirow[t]{4}{*}{ All ages } & Enhanced & $1.5 \%$ & $8.4 \%$ & $10.5 \%$ \\
\hline & New & $5.4 \%$ & $8.5 \%$ & $10.6 \%$ \\
\hline & Total & $6.9 \%$ & $16.9 \%$ & $21.1 \%$ \\
\hline & $n$ & 16992 & 15562 & 16359 \\
\hline
\end{tabular}

*The percentages have been increased by $22 \%$ to correct for a possible undercount of need in 1999 compared with the other 2 years.
Table 2 Percentage of people living with family carers recorded as needing respite breaks in each year 
Table 3 The numbers and percentage of respite users in the 1999 cohort $(n=2396)$ by respite service usage in 2003 and 2007

\begin{tabular}{lll}
\hline Outcome & 2003 & 2007 \\
\hline Continuing respite user & 1576 & 1309 \\
& $66 \%$ & $55 \%$ \\
Discontinued respite but person & 264 & 249 \\
remained with family & $11 \%$ & $10 \%$ \\
Discontinued respite due to & 293 & 422 \\
move to residential care & $12 \%$ & $17 \%$ \\
Discontinued respite for another & 263 & 416 \\
reason, for example, death, & $11 \%$ & $17 \%$ \\
move out of Ireland, or no longer in & & \\
need of intellectual disability service & & \\
\hline
\end{tabular}

2007. Although this represents a rise of 11 and $15 \%$, respectively, in those using respite within the 1999 cohort of family carers, these increases mask sizeable numbers of people who stopped their use of the respite. Thus the number of additional respite places provided by services over the 8-year period is smaller than the percentage rise in usage would suggest, with around 1000 new users in 2003 and a further 400 by 2007.

\section{The need for respite services}

A similar cohort analysis was undertaken in relation to the needs of families for respite provision. Table 4 reports the numbers of person who in 1999 were recorded as needing respite $(n=1130)$ and whether these needs had been met after 4 and 8 years. As the table shows, only a small proportion of persons with recorded needs (14 and 16\%, respectively) actually received respite services in future years with sizeable numbers still recorded as having a continuing need despite other persons in the cohort receiving respite services although they had no needs recorded in 1999 (see above). Moreover, around one-third of persons with a need noted in 1999 had no recorded need for respite in subsequent years.

\section{Section 3: Predictors of respite usage}

Binary logistic regressions were used to identify the significant predictors of respite usage in each of the three chosen years. The available variables from the national database were entered into the analysis at the same time and the Wald statistics used to ensure that each variable
Table 4 The numbers and percentages of persons in 1999 recorded as needing respite services and their needs in 2003 and $2007(n=1130)$

\begin{tabular}{lll}
\hline Outcome & 2003 & 2007 \\
\hline Continuing need recorded & 486 & 410 \\
& $43 \%$ & $36 \%$ \\
Now receiving respite & 162 & 176 \\
& $14 \%$ & $16 \%$ \\
Now in residential care & 41 & 68 \\
& $4 \%$ & $6 \%$ \\
No need recorded for respite care & 317 & 379 \\
& $28 \%$ & $34 \%$ \\
No need recorded - deceased, moved & 124 & 155 \\
from area or removed from database & $11 \%$ & $9 \%$ \\
\hline
\end{tabular}

enhanced the predictive power of the model. The results are shown in Table 5 in terms of the odds ratios along with significance levels of each predictor variable and for the model as a whole.

In all 3 years the highest predictor was the level of disability of the person, with those who had severe and profound disabilities initially up to 27 times more likely to have respite than those with mild disabilities. Although this odds ratio fell over the three chosen years, this client grouping remained the most likely to receive respite services. People with moderate disabilities were also more likely to receive respite over those with mild disabilities, although these odds also fell over the 3 chosen years.

Although females and adult persons aged 20 years and over were also significantly more likely to have respite services, these two variables did not add greatly to the odds ratio. However, single carers or relatives who were carers were no more likely to receive respite services than were two parent carers although there is the suggestion that as respite provision became more widely available by 2007, single carers had an increased likelihood of receiving it.

As Table 5 shows, there was a marked variation in the use of respite provision across the eight health service areas although this lessened over the 8 years (see Figure 1). In 1999, people resident in one area were over 11 times more likely to receive respite services than in the area with the lowest usage. With the increased availability of respite services across the state, this variation had been reduced especially in the 4 years to 2003 but by 2007 it had not been eliminated with people in one area twice as likely to receive services as in other areas. 
Table 5 Variables related to the usage of respite care in the three years

\begin{tabular}{|c|c|c|c|c|c|c|}
\hline \multirow[b]{2}{*}{ Variables } & \multicolumn{2}{|l|}{1999} & \multicolumn{2}{|l|}{2003} & \multicolumn{2}{|l|}{2007} \\
\hline & Sig $P<$ & Corrected OR & $\operatorname{Sig} P<$ & Corrected OR & Sig $P<$ & Corrected OR \\
\hline \multicolumn{7}{|l|}{ Level of disability } \\
\hline Mild (reference) & & 1.00 & & 1.00 & & 1.00 \\
\hline Moderate & 0.000 & 6.276 & 0.000 & 4.303 & 0.000 & 3.309 \\
\hline Severe/profound & 0.000 & 27.682 & 0.000 & 12.073 & 0.000 & 8.829 \\
\hline \multicolumn{7}{|l|}{ Health area } \\
\hline Reference area & & 1.00 & & 1.00 & & 1.00 \\
\hline Area 1 & 0.000 & 4.427 & 0.000 & 3.591 & 0.000 & 2.373 \\
\hline Area 2 & 0.000 & 11.340 & 0.000 & 3.629 & 0.000 & 1.941 \\
\hline Area 3 & 0.000 & 6.564 & 0.000 & 1.487 & 0.065 & 1.190 \\
\hline Area 4 & 0.000 & 4.064 & 0.000 & 1.827 & 0.000 & 1.578 \\
\hline Area 5 & 0.000 & 1.865 & 0.194 & 1.145 & 0.226 & 0.894 \\
\hline Area 6 & 0.000 & 5.455 & 0.000 & 3.145 & 0.000 & 1.517 \\
\hline Area 7 & 0.000 & 2.847 & 0.001 & 1.374 & 0.008 & 0.789 \\
\hline \multicolumn{7}{|l|}{ Age group } \\
\hline Child (reference) & & 1.00 & & 1.00 & & 1.00 \\
\hline Adult & 0.000 & 1.270 & 0.000 & 1.705 & 0.000 & 1.776 \\
\hline \multicolumn{7}{|l|}{ Gender } \\
\hline Male(reference) & & 1.00 & & 1.00 & & 1.00 \\
\hline Female & 0.004 & 1.157 & 0.000 & 1.299 & 0.000 & 1.255 \\
\hline \multicolumn{7}{|l|}{ Family carers } \\
\hline Two parent carers (reference) & & 1.00 & & 1.00 & & 1.00 \\
\hline Single carers & 0.022 & 1.156 & 0.245 & 1.062 & 0.003 & 1.147 \\
\hline Relatives & 0.547 & 0.948 & 0.683 & 0.970 & 0.684 & 0.972 \\
\hline
\end{tabular}

$1999 n=16072$ (94.6\%); Hosmer and Lemeshow test 40.26 d.f. 8, $P<0.001$ Nagelkerke $r 0.323 ; \chi^{2} 3251$, d.f. $=13, P<0.001$. $2003 n=14187$ (91.26\%); Hosmer and Lemeshow test 44.95 d.f. 8, $P<0.001$ Nagelkerke $r 0.256 ; \chi^{2} 2732$, d.f. $=13, P<0.001$. $2007 n=14078$ (86.1\%); Hosmer and Lemeshow test 38.33 d.f. 8, $P<0.001$ Nagelkerke $r$ 0.204; $\chi^{2} 2207$, d.f. $=13, P<0.001$

\section{Section 4: Predictors of need for respite services}

Binary logistic regressions were likewise used to identify significant predictors of the need for respite services as recorded in the database for the three chosen years. The results of these analyses are given in Table 6 although it should be noted that the resulting models were not as statistically robust as those for usage, particularly for the year 2007 as indicated by the Hosmer and Lemeshow Test.

As previously, it was the severity of disability that was the strongest predictor of need although the differential with moderate disabilities was not as marked as in the model for the use of respite. This suggests that the need for respite was seen as being as great for clients with moderate disabilities but preference was given to those with severe disabilities in the usage of services.
But once again, the odds ratios for need were outweighed by the variation across different geographical areas with recorded needs being up to five times greater in some areas than in others. Over the 8-year period this variation decreased but was still evident in particular areas. This is likely to reflect a continuing lack of provision as compared with other areas. In these analyses of need, neither age of person, nor gender, family carers were consistently significant predictors of need.

\section{Does need predict usage?}

The regression analyses for the use of respite services in 2003 (see Table 2) were repeated including the person's recorded need for respite as noted in 1999. This was repeated also for their use of respite in 2007. The recording of a need for respite was a significant predictor of using this form of service $(P<0.001)$ with a corrected odds ratio of 2.06 in 2003 and 2.91 in 2007. However, 


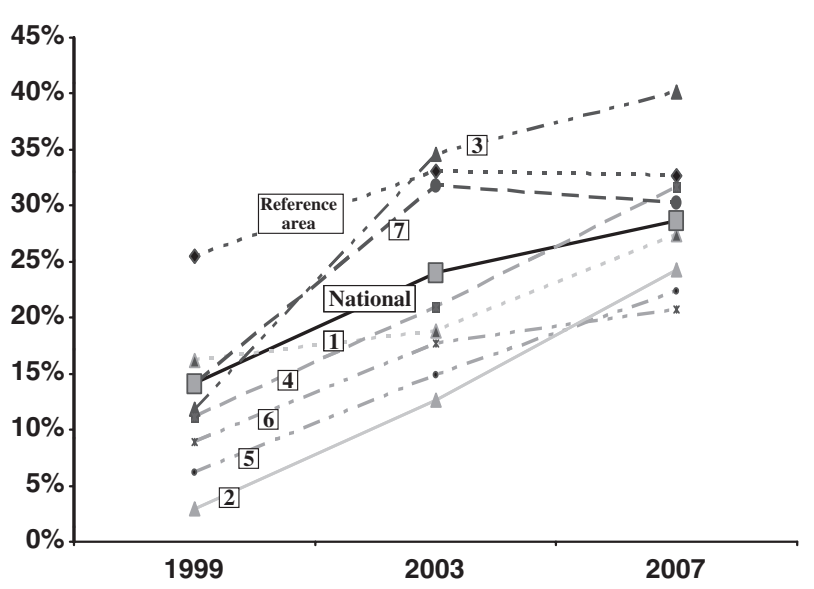

Figure I The proportions of family carers receiving respite services within each health area and nationally in 1999, 2003 and 2007.

the same pattern of odds ratios for the other variables persisted suggesting that although recorded need can make some contribution to receiving respite services, this is outweighed by level of disability and the health board area in which the person resides as these variables had higher odds ratios (see Table 5).

\section{Discussion}

The data clearly illustrate the geographical inequalities that existed in Ireland at the end of the last century in the provision of respite services and although they have been reduced they have not been eliminated. The period studied was a time of significant investment by the government in services for people with intellectual disabilities and one result was a doubling in the proportion of people receiving respite services over the 8-year period. Unfortunately, no information is available on the extra monies specifically spent on respite services so it is not possible to estimate the resources expended in connection with these developments. To date there have been few studies that have examined the cost-benefits of investment of respite provision which admittedly is a complex endeavour (Roberts 2001).

The increase in respite provision over the 8 years was accompanied by an even greater increase in the proportions of people recorded as needing it. This was expressed more in terms of children requiring a service they had never received, but over the years the rise in need was even more marked for those requiring enhanced provision to the services they were already receiving. The phenomena of increased provision acting as a stimulant to service demand are well attested in health service provision generally (Pencheon 1998) and for respite services in particular: families who expressed satisfaction with a service were likely to want to more of it (McConkey et al. 2004).

Increased demand can also arise from the families becoming more aware of the improved availability of services nationally or locally, and also because the gatekeepers to these services, such as social workers, may encourage families to use the services that they know are now more available. It will be interesting to see if in future, the recorded need continues to rise even when the proportion of families receiving respite levels off or perhaps falls, which could happen in the coming years due to economic cutbacks. Ongoing longitudinal analyses over longer time periods could provide some of the answers.

However, the concept of 'need for respite' requires more careful scrutiny. In this study the follow-up of families who both used and needed respite services provided some further insights. Over the 8 years, people's apparent need for respite fell considerably - by nearly $50 \%$ in 8 years as Table 3 shows. This means that the proportion of 'new users' is in fact much higher than a year-by-year comparison of total number of people using respite service would suggest (see Table 1), in that new users have taken the place of those who have stopped using existing services as well as availing of new services that have been created.

Some of the reduction in recorded need is understandable, such as when a person moves from family care into residential accommodation but around one in ten of people who had previously used respite services no longer did so, although their relative remained in the family. Possible reasons may include parental dissatisfaction with the service offered (McConkey \& Adams 2000); the service available to children is no longer available when they become adults because of an upper age limit (Ward et al. 2003); or the family are better able to cope (Chan \& Sigafoos 2000).

Likewise, an examination of changes in recorded need over the 8 years found that one third of persons had no longer a need recorded for respite services despite continuing to live with families. Similar reasons to those noted previously may account for this drop in need, for example, in the interim years the families may have used a respite service and found it to be unsatisfactory.

But these data also suggest that other families received respite services in preference to those whose need was recorded in 1999. Of the latter only a small proportion had become users of respite services $(16 \%$ of those who had expressed a need up to 8 years 
Table 6 Variables related to the need for respite care in the three years

\begin{tabular}{|c|c|c|c|c|c|c|}
\hline \multirow[b]{2}{*}{ Variables } & \multicolumn{2}{|l|}{1999} & \multicolumn{2}{|l|}{2003} & \multicolumn{2}{|l|}{2007} \\
\hline & Sig. $P<$ & Corrected OR & Sig $P<$ & Corrected OR & Sig $P<$ & Corrected $\mathrm{OR}$ \\
\hline \multicolumn{7}{|l|}{ Level of disability } \\
\hline Mild (reference) & & 1.00 & & 1.00 & & 1.00 \\
\hline Moderate & 0.000 & 3.092 & 0.000 & 2.654 & 0.000 & 2.317 \\
\hline Severe/profound & 0.000 & 3.607 & 0.000 & 4.443 & 0.000 & 3.868 \\
\hline \multicolumn{7}{|l|}{ Health area } \\
\hline Reference area & & 1.00 & & 1.00 & & 1.00 \\
\hline Area 1 & 0.004 & 1.806 & 0.087 & 1.231 & 0.074 & 1.213 \\
\hline Area 2 & 0.000 & 1.863 & 0.508 & 1.062 & 0.508 & 0.946 \\
\hline Area 3 & 0.063 & 1.463 & 0.012 & 0.742 & 0.000 & 0.647 \\
\hline Area 4 & 0.000 & 2.145 & 0.000 & 2.854 & 0.000 & 1.778 \\
\hline Area 5 & 0.523 & 1.141 & 0.224 & 0.878 & 0.233 & 0.891 \\
\hline Area 6 & 0.000 & 5.094 & 0.000 & 3.221 & 0.000 & 2.776 \\
\hline Area 7 & 0.000 & 3.597 & 0.000 & 1.440 & 0.307 & 1.097 \\
\hline \multicolumn{7}{|l|}{ Age group } \\
\hline Child (reference) & & 1.00 & & 1.00 & & 1.00 \\
\hline Adult & 0.000 & 0.630 & 0.380 & 0.958 & 0.000 & 1.236 \\
\hline \multicolumn{7}{|l|}{ Gender } \\
\hline Male (reference) & & 1.00 & & 1.00 & & 1.00 \\
\hline Female & 0.704 & 0.974 & 0.200 & 1.062 & 0.085 & 1.076 \\
\hline \multicolumn{7}{|l|}{ Family carers } \\
\hline Two parent carers (reference) & & 1.00 & & 1.00 & & 1.00 \\
\hline Single carers & 0.414 & 1.077 & 0.983 & 1.001 & 0.691 & 1.020 \\
\hline Relatives & 0.844 & 0.975 & 0.280 & 0.914 & 0.000 & 0.744 \\
\hline
\end{tabular}

$1999 n=16072$ (94.6\%); Hosmer and Lemeshow test 55.69 d.f. $8, P<0.001$

Nagelkerke $r 0.089 ; \chi^{2} 519$, d.f. $=13, P<0.001$.

$2003 n=14187$ (91.26\%); Hosmer and Lemeshow test 33.34 d.f. $8, P<0.001$

Nagelkerke $r 0.121 ; \chi^{2} 1074$, d.f. $=13, P<0.001$.

$2007 n=14078$ (86.1\%); Hosmer and Lemeshow test 14.99 d.f. $8, P<0.059$.

2008 Nagelkerke $r 0.107 ; \chi^{2} 1030$, d.f. $=13, P<0.001$.

previously) despite the expansion in provision nationally. Indeed, over a third had waited 8 years and still not received a service. Further research is required to illuminate what is meant by a 'need' for respite and perhaps identify the criteria that are used by services in meeting the needs of certain persons and families but not the needs of others. For example, in this study, the severity of disability and the availability of services seem to outweigh a recorded need for respite service. Equally greater efforts may be required to match the type of service provided to family wishes in order to match need more closely to service uptake.

The regression analyses provide some clues regarding perceived eligibility for respite services, although these analyses were limited by the sparsity of possible predictor variables recorded on the national dataset. However, the findings are all the stronger as they were replicated in the three chosen years. In common with various previous studies (e.g. Chadwick et al. 2002), the severity of the person's disability was the strongest predictor of accessing respite provision. Likewise, the regression analyses of recorded need also identified severity of disability as a significant predictor although interestingly not to the same extent. This suggests that severity of disability is a dominant criterion for accessing services when the supply of them exceeded demand.

Adult persons rather than children, and females with intellectual disabilities rather than males, were also more likely to receive respite although these were not consistently significant predictors of need. These may reflect a supply effect in that religious orders provided single-sex services more often for females than for males and although they may take male children for respite, this terminates once they become teenagers. 
Somewhat surprisingly, single carers were not significantly more likely to be users of, or to be recorded as more in need of respite services. This had been found to be a significant predictor of respite services in Northern Ireland partly because of the high numbers of one surviving parent caring for an ageing person with intellectual disability (McConkey 2005). The latter study also identified other variables that were related to respite usage, notably stress levels of carers and overactive behaviours in the person cared for. Hence, including in a national dataset additional variables relating to carers' characteristics and their changing demography, could increase the predictive model for respite usage. This would also assist the development of more explicit criteria for accessing respite services, an essential requirement to ensuring more equitable access to services.

Perhaps the most striking finding from the regression analyses is the geographical variation in both the provision of respite breaks and the recorded need for them. In 1999 in one health service area, families were 11 times more likely to access respite services compared with another area and although these odds had reduced over the 8-year period, the differences had not been eliminated. Similar findings have been reported for other countries (e.g. Kang \& Harrington 2008).

To a large extent these variations reflect the historical provision of intellectual disability services across Ireland and the absence of particular types of provision in certain regions. It is also a consequence of the Ireland's reliance on local providers instigating services rather than having a nationally driven, service development policy, although the latter started to evolve when increased resources became available and health services were re-organized. In all eight areas of the country, the proportion of respite users had increased but this happened in some areas more so than in others. This suggests that equity of provision across a country can take a long period of time to achieve especially when reliance is placed on differential increases in provision over time rather than transferring resources out of advantaged areas to those with less provision. Moreover, this inequality is compounded by the perverse relationship noted earlier of need increasing as provision increases. This phenomenon is also apparent to some extent in the regression analyses.

In sum then, this analysis of national longitudinal data has highlighted some of the complexities in reducing inequalities in the provision of respite services and in identifying the need for such services. More thorough analyses were not possible because the limited information that is collected as part of the national dataset.
However, as illustrated by this study, it would be possible to undertake more focused research with particular sub-samples of families to investigate specific hypotheses. It would also be advantageous if more explicit criteria were developed regarding a need for respite provision and the family's preferences for the form this provision might take. These adjustments would add to the value of any national database as a service planning tool.

\section{Correspondence}

Any correspondence should be directed to Professor Roy McConkey, Institute of Nursing Research, University of Ulster, Newtownabbey BT 37 OQB, UK (e-mail: r.mcconkey@ulster.ac.uk).

\section{Acknowledgments}

The data were sourced from the National Intellectual Disability Database. This is funded by the Department of Health and Children and is managed by the Health Research Board. Roy McConkey's post is jointly funded by the Health and Social Care Board for Northern Ireland. This research was sponsored in part by an EU Marie Curie award to the National Institute of Intellectual Disability, Trinity College Dublin that funded the Fellowships held by McConkey and Mannan.

\section{References}

Barron S., McConkey R. \& Mulvany F. (2006) Family carers of adult persons with intellectual disabilities on the island of Ireland. Journal of Policy and Practice in Intellectual Disability. 3, 87-94.

Beresford B. (1995) Expert Opinions: A National Survey of Parents Caring for a Severely Disabled Child. The Policy Press, Bristol.

Braddock D., Emerson E., Felce D. \& Stancliffe R.J. (2001) Living circumstances of children and adults with mental retardation or developmental disabilities in the United States, Canada, England and Wales, and Australia. Mental Retardation and Developmental Disabilities Research Reviews, 7, 115-121.

Chadwick O., Beecham J., Piroth N., Bernard S. \& Taylor E. (2002) Respite care of children with severe intellectual disability and their families: Who needs it? Who receives it? Child and Adolescent Mental Health, 7, 66-72.

Chan J. B. \& Sigafoos J. (2000) A review of child and family characteristics related to the use of respite care in developmental disability services. Child \& Youth Care Forum, 29, 27-37.

Department of Health (1990) Needs and Abilities: A Policy for the Intellectually Disabled. The Stationery Office, Dublin. 
Department of Health and Children (2005) Health Statistics. The Stationery Office, Dublin.

Emerson E. \& Hatton C. (2004) Estimating Future Need/Demand for Supports for Adults With Learning Disabilities in England. Lancaster University, Lancaster.

Hantrais L. (2004) Family Policy Matters: Responding to Family Change in Europe. The Policy Press, Bristol.

Haveman M., van Berkum G., Reijnders R. \& Heller T. (1997) Differences in service needs, time demands, and caregiving burden among parents of persons with mental retardation across the life cycle. Family Relations, 46, 417-425.

Kang T. \& Harrington C. (2008) Variation in types of service use and expenditures for individuals with developmental disabilities. Disability and Health Journal, 1, 30-41.

Kelly F., Craig S., McConkey R. \& Mannan H. (2009) Lone parent carers of people with intellectual disabilities in the Republic of Ireland. British Journal of Learning Disabilities, 37, 265-270.

Kelly F., Kelly C. \& Craig S. (2009) HRB Statistics Series: Annual Report of the National Intellectual Disability Database Committee. Health Research Board, Dublin.

Kelly F., McConkey R., Craig S. \& Mannan H. (submitted for publication) A national study of variations in the use of respite breaks by families in the Republic of Ireland.

Larson S.A., Lakin C.L., Anderson L., Kwak N., Lee J.H. \& Anderson D. (2001) Prevalence of mental retardation and developmental disabilities: estimates from the 1994/1995 National Health Interview Survey Disability Supplements. American Journal on Mental Retardation, 106, 231-254.

McConkey R. (2005) Fair shares? Supporting families caring for adult persons with intellectual disabilities Journal of Intellectual Disability Research, 49, 600-612.
McConkey R. \& Adams L. (2000) Do short breaks services for children with learning disabilities match family needs and preferences? Child: Care, Health and Development, 26, 429444.

McConkey R., Kelly F., Craig S. \& Mannan H. (submitted for publication) Moving from family care to residential and supported accommodation. A national, longitudinal study.

McConkey R., Truesdale M. \& Conliffe C. (2004) The features of short-break residential services valued by families who have children with multiple disabilities. Journal of Social Work, 4, 61-75.

MacDonald H. \& Callery P. (2004) Different meanings of respite: a study of parents, nurses and social workers caring for children with complex needs. Child: Care, Health and Development, 30, 279-288.

Pencheon D. (1998) Matching demand and supply fairly and efficiently. British Medical Journal, 316, 1665-1667.

Rizzolo M.C., Hemp R., Braddock D. \& Pomeranz-Essley A. (2004) The State of The States in Developmental Disabilities. AAMR, Washington, DC.

Roberts G. (2001) Supporting children with serious health care needs: analyzing the costs and benefits. Evaluation and the Health Professions, 24, 72-83.

Smiley E., Cooper S.-A., Miller S.M., Robertson P. \& Simpson N. (2002) Specialist health services for people with intellectual disability in Scotland. Journal of Intellectual Disability Research, 46, 585-593.

Ward L., Mallett R., Heslop P. \& Simons K. (2003) Transition planning: how well does it work for young people with learning disabilities and their families? British Journal of Special Education, 30, 132-137. 